\title{
Role of Adjunct Therapy of Antibiotics and Antioxidant Therapy in Dogs Suffering from Gastroenteritis
}

\author{
D. Kataria ${ }^{1 *}$, D. Agnihotri ${ }^{1}$, S. Kumar ${ }^{2}$, V. K. Jain ${ }^{1}$ and Y. Singh ${ }^{1}$ \\ ${ }^{1}$ Department of Veterinary Medicine, College of Veterinary Sciences, Lala Lajpat Rai \\ University of Veterinary and Animal Sciences, Hisar, Haryana-125004, India \\ ${ }^{2}$ Department of Veterinary Biochemistry and Physiology, College of Veterinary Sciences, Lala \\ Lajpat Rai University of Veterinary and Animal Sciences, Hisar, Haryana-125004, India \\ *Corresponding author
}

\section{A B S T R A C T}

\begin{tabular}{|l|}
\hline K e y w or d s \\
Adjunct therapy, \\
Antibiotics, \\
Antioxidant, Dogs, \\
Gastroenteritis
\end{tabular}

\section{Introduction}

Gastroenteritis may influence oxidative indices and such conditions may be targeted with supportive antioxidant therapy. In recent years, emphasis has been given on the antioxidants as the potential drugs of interest for management of diseases (Chandrasena et al., 2014). Excessive production of free radicals and their metabolites, called reactive oxygen species (ROS) exhibit several harmful effects which lead to oxidative damage of various metabolic products. Reactive Oxygen species (ROS) can be scavenged by antioxidant system which includes antioxidant enzymes like glutathione peroxidase, catalase and superoxide dismutase and non-enzymatic components involving vitamin $\mathrm{E}$, vitamin $\mathrm{C}$, vitamin $\mathrm{A}$ and selenium (Ighodaro and Akinloye, 2018). The antioxidant mechanism of vitamin $\mathrm{C}$ is based on the donation of hydrogen atom to lipid radicals, quenching of singlet oxygen and removal of molecular oxygen (Levine et al., 1999). N- 
acetylcysteine (NAC), the body's primary cellular antioxidant, is a precursor to glutathione and its role in glutathione maintenance and metabolism is well established (Kelly, 1998). Controlled studies to evaluate the oxidative stress on monogastric animals like dogs suffering from gastroenteritis are very few. Hence the present study was planned to investigate the oxidative stress indices in dogs suffering from gastroenteritis and to find the best therapeutic protocol involving antioxidants to ameliorate the oxidative stress and disease in gastroenteritic dogs.

\section{Materials and Methods}

The present study was conducted on fifty two dogs presented to Veterinary Clinical Complex (VCC), College of Veterinary Sciences, Lala Lajpat Rai University of Veterinary and Animal Sciences (LUVAS), Hisar with the history and clinical signs of vomition and diarrhoea. The dogs presented for routine health checkup/routine vaccination constituted the healthy control group. Blood samples were collected from cephalic/saphenous veins of the affected and control dogs. Two $\mathrm{ml}$ of blood was poured into $\mathrm{K}_{3}$ EDTA coated tube for hematological examination and three $\mathrm{ml}$ blood was poured into clot activator coated plain tube for obtaining serum. The separated serum were decanted in $2 \mathrm{ml}$ eppendorf tubes and stored at $-20^{\circ} \mathrm{C}$ till further processing. For the estimation of oxidative stress parameters, blood was poured into a tube coated with sodium heparin. Blood samples collected in heparinised tubes were centrifuged at 3000 rpm for 5 min and the separated plasma were decanted in $2 \mathrm{ml}$ eppendorf tubes and stored at $-20^{\circ} \mathrm{C}$ till further analysis. The blood samples were analyzed in automated hematology cell counter (MS4s, Melet Schlosing Lab.). The erythrocytic indices measured were haemoglobin $(\mathrm{Hb}) \mathrm{g} / \mathrm{dl}$, packed cell volume (PCV) per cent. The leucocytic indices measured were total leucocyte count (TLC) $\mathrm{m} / \mathrm{mm} 3$ and differential leucocyte count (DLC) (per cent) comprising of neutrophils (N) per cent, lymphocytes (L) per cent, monocytes (M) per cent, eosinophils (E) per cent and basophils (B) per cent were also measured. The thrombocytic indices measured included was total thrombocyte count (THR) $\mathrm{m} / \mathrm{mm}^{3}$. The serum samples were analyzed using automated random access clinical chemistry analyzer (EM Destiny 180, Erba Diagnostics Mannheim $\mathrm{GmbH})$. The liver function parameters measured were alanine amino transferase (ALT) (U/L), aspartate amino transferase (AST) (U/L) and total protein $(\mathrm{g} / \mathrm{dl})$. The kidney function parameters measured in serum were urea $(\mathrm{mg} / \mathrm{dl})$ and creatinine $(\mathrm{mg} / \mathrm{dl})$. Serum electrolytes were measured in EasyLyte EXPAND analyzer and included sodium $(\mathrm{mEq} / \mathrm{L})$, potassium $(\mathrm{mEq} / \mathrm{L})$ and chloride $(\mathrm{mEq} / \mathrm{L})$. For estimating oxidative stress parameters, blood samples were poured in heparinised tubes and centrifuged at $3000 \mathrm{rpm}$ for $5 \mathrm{~min}$ and the separated plasma samples were collected in 2 $\mathrm{ml}$ eppendorf tubes and stored at $-20^{\circ} \mathrm{C}$ till further processing. Superoxide dismutase (SOD) enzyme was measured as per the method described by Madesh and Balsubramaniam (1998). Glutathione Peroxidase (GSH-Px) activity was measured by method of Hafeman et al., (1974). The activity of catalase in plasma was determined as per the method of Aebi (1984). For trace elements estimation, one $\mathrm{ml}$ of serum sample was taken and to it $10 \mathrm{ml}$ of diacid mixture $\left(\mathrm{HNO}_{3}\right.$ and $\mathrm{HClO}_{4}$ in a ratio of 4:1) was added. The samples were kept overnight for digestion and then solutions were heated on hot plate until converted into transparent solution. The transparent solutions were poured into fresh plastic tubes and the final volume was made to $10 \mathrm{ml}$ by adding distilled water. These samples were analyzed in 
Atomic Absorption Spectrophotometer (AAS) machine (PerkinElmer Atomic Absorption Spectrophotometer PinAAcle 900T) after performing calibration with standard solutions. Dogs affected with gastroenteritis were randomly divided into six different treatment groups $\left(\mathrm{G}_{2}, \mathrm{G}_{3}, \mathrm{G}_{4}, \mathrm{G}_{5}, \mathrm{G}_{6}\right.$, and $\left.\mathrm{G}_{7}\right)$, consisting of six dogs in each group. Six apparently healthy dogs brought for routine health checkup and/or vaccination constituted the healthy control group $\left(\mathrm{G}_{1}\right)$. Dogs in different treatment groups were administered with antibiotics and antioxidants along with supportive therapy at various dosages and schedule as illustrated in the Table 1. The supportive and symptomatic treatment in different groups included the administration of intravenous fluid Ringer's Lactate (RL), Normal Saline Solution (NSS) or Dextrose Normal Saline (DNS) on the basis of dehydration status and the clinical condition, antacids (pantaprazole @ $1 \mathrm{mg} / \mathrm{kg}$ i.v.), antiemetic (prochlorperazine @ $0.2 \mathrm{mg} / \mathrm{kg}$ b.wt. i.m.), antihistaminic (pheniramine maleate @0.5 mg/kg b.wt. i.m.), antipyretic (analgin @25 mg/kg b.wt. i.m.), vitamin B complex, amino acid preparation, antifibrinolytic agents (Tranexamic acid @10 $\mathrm{mg} / \mathrm{kg}$ b.wt.) were administered as per the clinical condition of the animal.

Therapeutic evaluation was done on the basis of remission of clinical signs and restoration of normal hematological values. The blood and serum parameters were analyzed on day 0 (pre-treatment), day 3 and day 5 of therapy (post-treatment).

The data obtained was analyzed by suitable statistical methods using statistical software package (SPSS 16). To compare various parameters obtained in diseased dogs with the healthy control dogs, the independent t-test was applied. For analysis of various parameters observed for therapeutic efficacy, within and between the groups, two-way analysis of variance (ANOVA) with repeated measures was applied. The results are presented as Mean \pm S.E. at 5 per cent level of significance $(\mathrm{P}<0.05)$.

\section{Results and Discussion}

\section{Superoxide Dismutase (SOD)}

Comparative evaluation of oxidative stress parameters between the dogs suffering from gastroenteritis in different therapeutic groups and control group is depicted in Table 2. All the dogs in the therapeutic groups showed significantly lowered mean values $(\mathrm{P}<0.05)$ of superoxide dismutase when compared to the mean values of SOD in the control group of dogs at the start of therapy on day 0 . A nonsignificant increase $(\mathrm{P}<0.05)$ in the mean levels of SOD enzyme was observed in all the dogs under treatment in groups G2, G3, G4 and G5 on day 3 and day 5 of therapy. A significant increase $(\mathrm{P}<0.05)$ in the mean levels of SOD was observed within groups G6 and G7 on day 3 and day 5 of therapy. A significant difference $(\mathrm{P}<0.05)$ in the mean SOD activity was observed in groups G2, G4, G6 and G7 on day 3 and day 5 of treatment as compared control group. Similarly highly significant difference $(\mathrm{P}<0.05)$ in the mean SOD activity was observed in groups G3 and G4 on day 3 and day 5 as compared to the control group. Increased activity of SOD was observed in all the treatment groups after five days of treatment but significantly higher increase was observed in the groups G2, G4, G6, G7 which were administered antioxidants along with antibiotics than the groups G3 and G5 which were administered only antibiotics. Significant increase $(\mathrm{P}<0.05)$ was also observed within the groups G6 and G7 from day 0 to day 5 of treatment where both antioxidants vitamin $\mathrm{C}$ and NAC were administered showing that the combined antioxidant therapy is more effective in amelioration of oxidative stress as indicated 
by the increased levels of SOD on day 5 of therapy.

\section{Catalase (CAT)}

Significantly lowered activity $(\mathrm{P}<0.05)$ of mean catalase levels was observed in all the dogs in different treatment groups as compared to the control group of dogs on day 0 . A non-significant increase $(\mathrm{P}<0.05)$ in the catalase activity was observed within all the treatment groups on day 3 and 5 of therapy. In group G6 a significant increase $(\mathrm{P}<0.05)$ in the mean catalase activity was observed after treatment on day 3 and day 5 of therapy. Dogs in group G6 showed significantly higher increase $(\mathrm{P}<0.05)$ in the mean catalase activity as compared to the other groups on day 3 and day 5 of treatment. Significant increase $(\mathrm{P}<0.05)$ in catalase activity in groups G2, G3, G4 and G7 on day 3 of therapy was observed as compared to group G5. Similarly groups G2, G3 and G7 showed more significant increase $(\mathrm{P}<0.05)$ in the mean levels of catalase activity than groups G4 and G5 on day 5 of therapy as compared to the control group. Group G6 showed higher significant increase $(\mathrm{P}<0.05)$ in catalase activity on day 5 of treatment than rest of the groups. Groups G2 and G3 showed more improved levels of catalase than groups G4 and G5 while group G7 showed higher increased activity of catalase than groups G4 and G5 on day 5.

\section{Glutathione peroxidase (GPx)}

All the treatment groups i.e. G2, G3, G4, G5, G6 and G7 showed significantly lower $(\mathrm{P}<0.05)$ levels of mean glutathione peroxidase activity than healthy control group at day 0 before the start of therapy. Groups G2, G3 and G5 showed lower glutathione peroxidase activity as compared to groups G4, G6 and G7 at the start of treatment on day 0 . A significant increase $(\mathrm{P}<0.05)$ was observed in the glutathione peroxidase activity in all the treatment groups on day 3 and 5 as a response to therapy. All the therapeutic groups except group G5 showed significantly increased $(\mathrm{P}<0.05)$ mean levels of glutathione peroxidase activity on day 3 of therapy. Dogs of group G6 showed maximum significant increase $(\mathrm{P}<0.05)$ in the mean levels of glutathione peroxidase activity than the groups G2, G3, G4, G5 and G7 on day 5 of therapy. On day 5 of therapy, groups G2, G4 and G7 showed more significant increase $(\mathrm{P}<0.05)$ in glutathione peroxidase activity as compared to group G3.

A significant increase $(\mathrm{P}<0.05)$ was observed in the glutathione peroxidase activity in all the treatment groups on day 3 and day 5 of therapy. Group G6 (ceftriaxone-tazobactum along with vitamin $\mathrm{C}$ and NAC) and group G7 (ampicillin-cloxacillin along with vitamin $\mathrm{C}$ and NAC) showed higher increase in glutathione peroxidase activity than rest of the treatment groups on day 5 of therapy.

Significantly $(\mathrm{P}<0.05)$ decreased activity of different antioxidant enzymes (SOD, CAT and GPx) was observed in plasma of the affected dogs. Kendall et al., (2017) found deficiency in GPx activity in anaemic dogs while Beigh et al., (2014) found reduced levels of SOD and CAT in dogs affected with zinc responsive dermatosis. In accordance with these studies Singh and Dimri (2013) also reported decreased activities SOD, GPx, CAT, glutathione-S-transferase (GST) in dogs affected with sarcoptic mange. On the contrary, Panda et al., (2009) observed higher activities of SOD and CAT in the dogs affected with canine parvoviral gastroenteritis. In parallel to the present observations Rautray et al., (2016) reported decreased enzymatic activities of SOD and CAT in erythrocyte lysate of dogs suffering from gastroenteritis. 
Both increased and decreased levels of antioxidant markers have been reported in different diseases as a consequence of enhanced reactive oxygen species (ROS) production either by up-regulation of enzyme activity or by utilization of the antioxidant enzymes to counter the ROS (Panda et al., 2009). Significant reduction in antioxidant biomarkers found in diseased dogs could be attributed to the consumption of antioxidants that act as "scavengers" of free radicals during the oxidative processes (Crnogaj et al., 2017). NAC proved to be a reliable and effective treatment option in case of gastroenteritis. Viviano and Vander Wielen (2013) also reported NAC supplementation in treatment during the first 48 hours of hospitalization in dogs stabilized erythrocyte glutathione concentrations and decreased oxidative stress. Similarly, Patel et al., (2018) also found that NAC along with vitamin $\mathrm{C}$ and vitamin $\mathrm{E}$ effectively treated gastritis and peptic ulcers in dogs.

\section{Copper}

Comparative evaluation of serum trace minerals between the dogs suffering from gastroenteritis in different therapeutic groups and the control dogs from day 0 to day 5 in response to the therapy is depicted in Table 3. All the treatment groups i.e. G2, G3, G4, G5, G6 and G7 showed significantly lower mean levels $(\mathrm{P}<0.05)$ of copper than the control group at the start of therapy on day 0. Groups G2, G3 and G5 showed highly significant lower mean levels of copper than groups G4, G6 and G7 at the start of treatment on day 0 . A non-significant increase $(\mathrm{P}<0.05)$ was observed in mean copper levels within all the treatment groups on day 3 and day 5 of therapy. Highly significant increase $(\mathrm{P}<0.05)$ was observed in groups G4, G6 and G7 followed by groups G5, G2 and G3 as a response to therapy on day 3 and day 5 of treatment. More significant increase $(\mathrm{P}<0.05)$ in the levels of copper was observed in groups G4, G6 and G7 followed by group G5, G2 and G3 on day 3 and day 5 of initiation of therapy.

\section{Iron}

All the treatment groups showed significantly lowered $(\mathrm{P}<0.05)$ mean levels of iron as compared to the control group at the start of therapy on day 0. Groups G2, G4 and G7 showed higher mean levels of iron than groups G3, G5 and G6 at the start of treatment at day 0 . There was a nonsignificant increase $(\mathrm{P}<0.05)$ in the mean serum iron levels within all the treatment groups on day 3 and day 5 of therapy. A significant increase $(\mathrm{P}<0.05)$ in the mean levels of iron within group G6 was observed on day 3 and day 5 of therapy. The treatment groups G2, G4 and G7 showed significantly $(\mathrm{P}<0.05)$ higher mean levels of iron as compared to groups G3, G5 and G6 at the start of treatment on day 0. Groups G2 and G4 showed a higher significant increase $(\mathrm{P}<0.05)$ in the mean levels of iron than groups G6 and G7, while groups G3 and G5 showed a low though significant increase $(\mathrm{P}<0.05)$ on day 3 of therapy. Groups $\mathrm{G} 2$ and G7 showed more significant increase $(\mathrm{P}<0.05)$ in mean iron levels followed by groups G6 and G4 while least significant increase $(\mathrm{P}<0.05)$ in the levels of iron was observed in groups G3 and G5 on day 5 of therapy. Groups G2 and G7 showed more significant increase $(\mathrm{P}<0.05)$ in iron levels followed by groups G6 and G4 respectively while least significant increase $(\mathrm{P}<0.05)$ in the levels of iron was observed in groups G3 and G5 on day 5 after the initiation of therapy.

\section{Zinc}

Dogs in all the therapeutic groups showed significantly lower mean levels $(\mathrm{P}<0.05)$ of zinc as compared to the healthy control group 
at the start of therapy on day 0 . There was a non-significant increase $(\mathrm{P}<0.05)$ in serum zinc levels within the groups G2, G3 and G4 on day 3 and 5 of the treatment while significant increase $(\mathrm{P}<0.05)$ in the levels of mean zinc was observed within groups G5, G6 and G7 on day 3 and day 5 of therapy. Significant decrease $(\mathrm{P}<0.05)$ in the mean values of zinc was observed in all the therapeutic groups as compared to the control group G1 on day 0 and day 3 of therapy while no difference was observed in the mean levels of iron in different treatment groups on day 5 of therapy. There was a non-significant increase $(\mathrm{P}<0.05)$ in serum zinc levels within the groups G2, G3 and G4 on day 3 and 5 of the treatment while significant increase $(\mathrm{P}<0.05)$ in the levels of mean zinc was observed within groups G5, G6 and G7 on day 3 and day 5 of therapy.

In this study all the trace minerals levels were found to be increased towards normalization in comparison to healthy control dogs after five days of treatment. Mahadapaa and Dey (2018) found increased levels of zinc, iron and copper in their study post three weeks treatment in dogs infected with Toxocara canis. Heidarpour et al., (2013) reported decreased levels of copper, iron and zinc in sheep affected with liver cystic echinococcosis. Though reduced total antioxidant status and reduced SOD was observed by them in the affected sheep. GPx levels were found to be higher as compared to the healthy control which is in contrast to the findings of the present study. Trace minerals levels were found to be restored towards normalization in present study explained that the antibiotic along with antioxidant therapy (Vitamin $\mathrm{C}$ and NAC) helped in declining oxidative stress by boosting antioxidant enzymes activities and by increasing absorption of micronutrients from intestinal epithelium after five days of treatment.

Table.1 Therapeutic regimen of different groups

\begin{tabular}{|c|c|c|c|}
\hline Group & Number of animals & Antibiotic & Antioxidant \\
\hline 1 & 6 & Nil & Nil \\
\hline 2 & 6 & $\begin{array}{c}\text { Ceftriaxone-Tazobactum @ } 25 \mathrm{mg} / \mathrm{kg} \\
\text { b.wt. o.d. i.m. }\end{array}$ & $\begin{array}{c}\text { Vitamin C@20 mg/kg b.wt. o.d. } \\
\text { i.v. }\end{array}$ \\
\hline 3 & 6 & $\begin{array}{c}\text { Ceftriaxone-Tazobactum @25 mg/kg } \\
\text { b.wt. o.d.i.m. }\end{array}$ & Nil \\
\hline 4 & 6 & $\begin{array}{l}\text { Ampicillin-Cloxacillin@ @ } 10 \mathrm{mg} / \mathrm{kg} \\
\text { b.wt. b.i.d. i.m. + Metronidazole @ } 15 \\
\text { mg/kg b.wt. t.i.d.i.v. }\end{array}$ & $\begin{array}{l}\text { N-acetylcysteine (NAC) @70 } \\
\text { mg/kg b.wt. o.d. i.v. }\end{array}$ \\
\hline 5 & 6 & $\begin{array}{l}\text { Ampicillin-Cloxacillin@ @ } 10 \text { mg/kg } \\
\text { b.wt. b.i.d. i.m. + Metronidazole @ } 15 \\
\text { mg/kg b.wt. t.i.d.i.v. }\end{array}$ & Nil \\
\hline 6 & 6 & $\begin{array}{c}\text { Ceftriaxone-Tazobactum @25 mg/kg } \\
\text { b.wt. o.d.i.m. }\end{array}$ & $\begin{array}{l}\mathrm{N} \text {-acetylcysteine (NAC) @ } 70 \\
\text { mg//kg b.wt. o.d. i.v. + Vitamin C } \\
\text { @ } 20 \text { mg/kg b.wt. o.d. i.v. }\end{array}$ \\
\hline 7 & 6 & $\begin{array}{l}\text { Ampicillin-Cloxacillin@ @ } 10 \text { mg/kg } \\
\text { b.wt. b.i.d. i.m. + Metronidazole @ } 15 \\
\text { mg/kg b.wt. t.i.d.i.v. }\end{array}$ & $\begin{array}{l}\mathrm{N} \text {-acetylcysteine (NAC) @ } 70 \\
\text { mg/kg b.wt. o.d. i.v. + Vitamin C } \\
\text { @ } 20 \text { mg/kg b.wt. o.d. i.v. }\end{array}$ \\
\hline
\end{tabular}


Table.2 Oxidative stress parameters (Mean \pm S.E.) of gastroenteritic dogs in different therapeutic groups

\begin{tabular}{|c|c|c|c|c|c|c|c|c|}
\hline Parameters & Day & $\begin{array}{c}\text { Group } 1 \\
(n=6)\end{array}$ & $\begin{array}{c}\text { Group } 2 \\
(n=6)\end{array}$ & $\begin{array}{c}\text { Group } 3 \\
(n=6)\end{array}$ & $\begin{array}{c}\text { Group } 4 \\
(n=6)\end{array}$ & $\begin{array}{c}\text { Group } 5 \\
(n=6)\end{array}$ & $\begin{array}{c}\text { Group } 6 \\
(n=6)\end{array}$ & $\begin{array}{c}\text { Group } 7 \\
(n=6)\end{array}$ \\
\hline \multirow{3}{*}{$\begin{array}{c}\text { SOD } \\
\text { (Units/g } \\
\text { protein) }\end{array}$} & 0 & $12.67 \pm 0.95^{\mathrm{B}}$ & $8.40 \pm 0.83^{\mathrm{A}}$ & $7.45 \pm 1.08^{\mathrm{A}}$ & $6.78 \pm 0.63^{\mathrm{A}}$ & $6.35 \pm 1.38^{\mathrm{A}}$ & $8.05 \pm 1.38^{\mathrm{Aa}}$ & $7.91 \pm 0.49^{\mathrm{Aa}}$ \\
\hline & 3 & $12.67 \pm 0.95^{\mathrm{B}}$ & $9.12 \pm 2.53^{\mathrm{AB}}$ & $7.26 \pm 1.01^{\mathrm{A}}$ & $8.09 \pm 0.85^{\mathrm{A}}$ & $7.59 \pm 1.13^{\mathrm{A}}$ & $9.30 \pm 0.38^{\mathrm{ABb}}$ & $9.36 \pm 0.28^{\mathrm{ABb}}$ \\
\hline & 5 & $12.67 \pm 0.95^{\mathrm{B}}$ & $10.87 \pm 0.27^{\mathrm{AB}}$ & $8.56 \pm 0.87^{\mathrm{A}}$ & $9.79 \pm 1.07^{\mathrm{AB}}$ & $8.82 \pm 0.96^{\mathrm{A}}$ & $11.38 \pm 1.44^{\mathrm{ABc}}$ & $10.63 \pm 0.24^{\mathrm{ABc}}$ \\
\hline \multirow{3}{*}{$\begin{array}{c}\text { Catalase } \\
\left(\mathrm{mmol} \mathrm{H}_{2} \mathrm{O}_{2}\right. \\
\text { utilised } / \mathrm{min} / \mathrm{g} \\
\text { protein) }\end{array}$} & 0 & $403.67 \pm 15.69^{\mathrm{B}}$ & $277.17 \pm 14.85^{\mathrm{A}}$ & $305.83 \pm 23.69^{\mathrm{A}}$ & $250.67 \pm 14.33^{\mathrm{A}}$ & $252.5 \pm 28.96^{\mathrm{A}}$ & $285.83 \pm 23.58^{\text {Aa }}$ & $270.67 \pm 20.19^{\mathrm{A}}$ \\
\hline & 3 & $403.67 \pm 15.69^{C}$ & $288.33 \pm 25.30^{\mathrm{AB}}$ & $278.67 \pm 13.142^{\mathrm{AB}}$ & $284.67 \pm 16.20^{\mathrm{A}}$ & $251.17 \pm 11.81^{\mathrm{A}}$ & $311.67 \pm 18.12^{\mathrm{Ba}}$ & $286.5 \pm 18.03^{\mathrm{AB}}$ \\
\hline & 5 & $403.67 \pm 15.69^{\mathrm{D}}$ & $330.33 \pm 13.69^{\mathrm{BC}}$ & $322.5 \pm 15.36^{\mathrm{ABC}}$ & $306.83 \pm 16.80^{\mathrm{AB}}$ & $274.67 \pm 17.18^{\mathrm{A}}$ & $371.33 \pm 12.37^{\mathrm{CDb}}$ & $321.67 \pm 20.56^{\mathrm{ABC}}$ \\
\hline \multirow{3}{*}{$\begin{array}{c}\text { GPx } \\
\text { (Units/g } \\
\text { protein) }\end{array}$} & 0 & $3889.43 \pm 103.23^{C}$ & $1725.45 \pm 252.50^{\mathrm{Aa}}$ & $1690.95 \pm 258.92^{\mathrm{Aa}}$ & $2517 \pm 167.17^{\mathrm{Ba}}$ & $1567.6 \pm 247.32^{\mathrm{Aa}}$ & $1939.18 \pm 269.15^{\mathrm{ABa}}$ & $1808.47 \pm 257.38^{\mathrm{ABa}}$ \\
\hline & 3 & $3889.43 \pm 103.23^{C}$ & $2325.02 \pm 203.59^{\mathrm{ABab}}$ & $2138.60 \pm 262.21^{\mathrm{ABa}}$ & $2742.85 \pm 140.82^{\mathrm{Bab}}$ & $1965.1 \pm 176.39^{\text {Aab }}$ & $2307.73 \pm 196.14^{\mathrm{ABa}}$ & $2195.17 \pm 288.98^{\mathrm{ABa}}$ \\
\hline & 5 & $3889.43 \pm 103.23^{\mathrm{C}}$ & $2932.75 \pm 194.79^{\mathrm{ABb}}$ & $2646.62 \pm 210.62^{\mathrm{Ab}}$ & $3123.43 \pm 215.79^{\mathrm{ABb}}$ & $2655.73 \pm 266.97^{\mathrm{Ab}}$ & $3381.07 \pm 139.68^{\mathrm{BCb}}$ & $3145.17 \pm 178.69^{\mathrm{ABb}}$ \\
\hline
\end{tabular}

The means bearing different superscripts $(\mathrm{a}, \mathrm{b}$ and $\mathrm{c})$ differ significantly $(\mathrm{P}<0.05)$ within the groups.

The means bearing different superscripts $(A, B, C$ and $D)$ differ significantly $(P<0.05)$ between the groups.

Table. 2 Trace minerals (Mean \pm S.E.) in gastroenteritic dogs in different therapeutic groups

\begin{tabular}{|c|c|c|c|c|c|c|c|c|}
\hline Parameters & Day & $\begin{array}{c}\text { Group } 1 \\
(n=6)\end{array}$ & $\begin{array}{c}\text { Group } 2 \\
(n=6)\end{array}$ & $\begin{array}{c}\text { Group } 3 \\
(n=6)\end{array}$ & $\begin{array}{c}\text { Group } 4 \\
(n=6)\end{array}$ & $\begin{array}{c}\text { Group } 5 \\
(n=6)\end{array}$ & $\begin{array}{c}\text { Group } 6 \\
(n=6)\end{array}$ & $\begin{array}{c}\text { Group } 7 \\
(n=6)\end{array}$ \\
\hline \multirow{3}{*}{$\begin{array}{c}\text { Copper } \\
(\mathrm{ppm})\end{array}$} & 0 & $4.55 \pm 0.29^{C}$ & $2.43 \pm 0.11^{\mathrm{A}}$ & $2.50 \pm 0.12^{\mathrm{A}}$ & $2.97 \pm 0.19^{\mathrm{AB}}$ & $2.57 \pm 0.12^{\mathrm{A}}$ & $2.86 \pm 0.19^{\mathrm{AB}}$ & $2.90 \pm 0.17^{\mathrm{AB}}$ \\
\hline & 3 & $4.55 \pm 0.29^{C}$ & $2.73 \pm 0.14^{\mathrm{AB}}$ & $2.66 \pm 0.18^{\mathrm{A}}$ & $3.02 \pm 0.18^{\mathrm{B}}$ & $2.79 \pm 0.08^{\mathrm{AB}}$ & $3.09 \pm 0.16^{\mathrm{B}}$ & $3.04 \pm 0.16^{\mathrm{B}}$ \\
\hline & 5 & $4.55 \pm 0.29^{C}$ & $2.83 \pm 0.04^{\mathrm{AB}}$ & $2.75 \pm 0.04^{\mathrm{A}}$ & $3.19 \pm 0.15^{\mathrm{B}}$ & $2.90 \pm 0.09^{\mathrm{AB}}$ & $3.25 \pm 0.11^{\mathrm{B}}$ & $3.26 \pm 0.13^{B}$ \\
\hline \multirow{3}{*}{$\begin{array}{c}\text { Iron } \\
(\mathbf{p p m})\end{array}$} & 0 & $57.82 \pm 0.42^{C}$ & $55.46 \pm 0.56^{\mathrm{AB}}$ & $54.58 \pm 1.12^{\mathrm{A}}$ & $55.67 \pm 0.24^{\mathrm{AB}}$ & $54.09 \pm 0.58^{\mathrm{A}}$ & $54.18 \pm 0.35^{\mathrm{Aa}}$ & $55.87 \pm 0.46^{\mathrm{AB}}$ \\
\hline & 3 & $57.82 \pm 0.42^{C}$ & $56.33 \pm 0.85^{\mathrm{B}}$ & $55.33 \pm 1.15^{\mathrm{A}}$ & $56.18 \pm 0.42^{\mathrm{B}}$ & $55.48 \pm 0.53^{\mathrm{A}}$ & $55.51 \pm 0.45^{\mathrm{ABab}}$ & $56.13 \pm 0.63^{\mathrm{AB}}$ \\
\hline & 5 & $57.82 \pm 0.42^{C}$ & $57.12 \pm 0.59^{C}$ & $56.19 \pm 0.75^{A}$ & $56.86 \pm 0.38^{\mathrm{AB}}$ & $56.24 \pm 0.41^{\mathrm{A}}$ & $57.45 \pm 0.20^{\mathrm{BCb}}$ & $57.82 \pm 0.60^{C}$ \\
\hline \multirow{3}{*}{$\begin{array}{c}\text { Zinc } \\
(\mathbf{p p m})\end{array}$} & 0 & $3.92 \pm 0.28^{\mathrm{B}}$ & $3.09 \pm 0.13^{\mathrm{A}}$ & $3.03 \pm 0.04^{\mathrm{A}}$ & $3.04 \pm 0.23^{\mathrm{A}}$ & $2.70 \pm 0.12^{\mathrm{Aa}}$ & $3.05 \pm 0.16^{\mathrm{Aa}}$ & $2.84 \pm 0.13^{\mathrm{Aa}}$ \\
\hline & 3 & $3.92 \pm 0.28^{\mathrm{B}}$ & $3.17 \pm 0.15^{\mathrm{A}}$ & $3.15 \pm 0.15^{\mathrm{A}}$ & $3.07 \pm 0.10^{\mathrm{A}}$ & $3.06 \pm 0.17^{\mathrm{Ab}}$ & $3.17 \pm 0.09^{\mathrm{Ab}}$ & $3.28 \pm 0.08^{\mathrm{Ab}}$ \\
\hline & 5 & $3.92 \pm 0.28$ & $3.46 \pm 0.11$ & $3.26 \pm 0.05$ & $3.30 \pm 0.13$ & $3.28 \pm 0.11^{b}$ & $3.88 \pm 0.30^{c}$ & $3.86 \pm 0.14^{\mathrm{c}}$ \\
\hline
\end{tabular}

The means bearing different superscripts $(\mathrm{a}, \mathrm{b}$ and $\mathrm{c})$ differ significantly $(\mathrm{P}<0.05)$ within the groups.

The means bearing different superscripts $(\mathrm{A}, \mathrm{B}$ and $\mathrm{C})$ differ significantly $(\mathrm{P}<0.05)$ between the groups. 
In conclusion significant low levels of antioxidant enzymes like Superoxide Dismutase, Catalase and Glutathione peroxidase and trace minerals like copper, iron and zinc are significant oxidative stress markers in gastro-enteric infections of dogs. Adjunct therapy with Vitamin $\mathrm{C}$ and $\mathrm{N}$ acetylcysteine have an additive effect in amelioration of oxidative stress during gastroenteritis in dogs and assisted in early and uneventful recovery with restoration of haemato-biochemical parameters.

\section{References}

Aebi, H. (1984). Catalase in vitro. Methods Enzymol., 105: 121-126.

Beigh, S. A., Soodan, J. S., Nazki, S. and Khan, A. M. (2014). Oxidative stress, hematobiochemical parameters, trace elements and vitamins in dogs with zinc responsive dermatosis. Veterinarski Arhiv, 84(6): 591-600.

Chandrasena, L. G., Peiris, H., Kamani, J., Wanigasuriya, P., Jayaratne, S. D., Wijayasiri, W. A. A. and Wijesekara, G. U. S. (2014). Antioxidants in patients with dengue viral infection. Southeast Asian J. Trop. Med. Pub. Health, 45(5): 1015.

Crnogaj, M., Ceron, J. J., Smit, I., Kis, I., Gotic, J., Brkljacic, M., Matijatko, V., Rubio, C. P., Kucer, N. and Mrljak, V. (2017). Relation of antioxidant status at admission and disease severity and outcome in dogs naturally infected with Babesia canis canis. Bio. Med. Central Vet. Res., 13(1): 114.

Hafeman, D. G., Sunde, R. A. and Hoekstra, W. G. (1974). Effect of dietary selenium on erythrocyte and liver glutathione peroxidase in the rat. $J$. Nutri., 104(5): 580-587.

Heidarpour, M., Mohri, M., Borji, H. and Moghaddas, E. (2013). Oxidant/antioxidant balance and trace elements status in sheep with liver cystic echinococcosis. Comp. Clin. Pathol., 22(6): 1043-1049.

Ighodaro, O. M. and Akinloye, O. A. (2018). First line defence antioxidantssuperoxide dismutase (SOD), catalase (CAT) and glutathione peroxidase (GPX): Their fundamental role in the entire antioxidant defence grid. Alexandsria J. Med., 54(4): 287-293.

Kelly, G. S. (1998). Clinical applications of N-acetylcysteine. Alt. Med. Rev., 3(2): 114-127.

Kendall, A., Woolcock, A., Brooks, A. and Moore, G. E. (2017). Glutathione peroxidase activity, plasma total antioxidant capacity, and urinary F2isoprostanes as markers of oxidative stress in anemic dogs. J. Vet. Intern. Med., 31(6): 1700-1707.

Levine, M., Rumsey, S. C., Daruwala, R., Park, J. B. and Wang, Y. (1999). Criteria and recommendations for vitamin C intake. J. Am. Med. Assoc., 281(15): 1415-1423.

Madesh, M. and Balasubramanian, K. A. (1998). Microtiter plate assay for superoxide dismutase using MTT reduction by superoxide. Ind. $J$. Biochemist. Biophysics, 35(3): 184188.

Mahadappa, P. and Dey, S. (2018). Effects of Toxocara canis Infection and Albendazole Treatment on Oxidative/Nitrosative Stress and Trace Element Status in Dogs. Intern. J. Livestock Res., 8(4): 144-153.

Panda, D., Patra, R. C., Nandi, S. and Swarup, D. (2009). Oxidative stress indices in gastroenteritis in dogs with canine parvoviral infection. Res. Vet. Sci., 86: 36-42.

Patel, P. K., Patel, S. K., Dixit, S. K. and Rathore, R. S. (2018). Gastritis and Peptic Ulcer Diseases in Dogs: A Review. Int. J. Curr. Microbiol. App. 
Sci., 7(3): 2475-2501.

Rautray, A. K., Patra, R. C., Parida, G. S., Sardar, K. K. and Niranjan, P. (2016). Erythrocytic oxidative stress indices and clinico-biochemical alterations in gastroenteritis in dogs with varied clinical scores. Philippine J. Vet. Anim. Sci., 42(2): 120-128.

Singh, S. K. and Dimri, U. (2013). Amelioration of sarcoptic mangeinduced oxidative stress and apoptosis in dogs by using Calendula officinalis flower extracts. Int. Scholarly Res. Notices Oxid. Med., 657672: 1-8.

Viviano, K. R. and Vander Wielen, B. (2013). Effect of N-acetylcysteine supplementation on intracellular glutathione, urine isoprostanes, clinical score, and survival in hospitalized ill dogs. J. Vet. Int. Med., 27(2): 250-258.

\section{How to cite this article:}

Kataria, D., D. Agnihotri, S. Kumar, V. K. Jain and Singh, Y. 2020. Role of Adjunct Therapy of Antibiotics and Antioxidant Therapy in Dogs Suffering from Gastroenteritis. Int.J.Curr.Microbiol.App.Sci. 9(02): 1780-1788. doi: https://doi.org/10.20546/ijcmas.2020.902.203 